\title{
Functionality of Family and Children in Relation to Gender, Age and Emotional Abilities of Children and Family Structure
}

\author{
Dragana Šćepović, PhD \\ Department of Social Work, University of Banjaluka, Faculty of Political science, Bosnia and Herzegovina.
}

\begin{abstract}
The subject of this empirical research is a comprehensive view of the impact of functionality and dysfunctionality of the family on the emotional skills of children in relation to sex, age of children and the family structure. The main objective of the research is to determine whether there is a link between functionality and dysfunctionality of family and emotional skills of children in relation to sex, age of children and the family structure. The study used the basic, general, and data collection methods (test method). Test method, scaling technique was used in the empirical part of the research for data collection using instrument questionnaire of emotional competence. In accordance with the hypothesis of research we were examined whether there is a statistically significant difference in the level of development of emotional abilities between the functional groups of children from families and groups of children from dysfunctional families in relation to age (12-13,14, 15 and 16 years), in relation to gender (male and female) in relation to family structure (complete and incomplete). The results showed that the statistically significant difference and clearly defined border between the groups in relation to: emotional abilities and age (12-13 years) - Analysis MANOVA $p=.011$ and discriminant analysis $p=.011$; emotional skills and gender (male) - Analysis MANOVA $p=.042$ and discriminant analysis $p=.046$; and emotional skills, and family structure (incomplete) - Analysis MANOVA $p=.138$ and discriminant analysis $p=$ .069. The results showed that it was possible to define the characteristics, the homogeneity of the group and the distance between them, which confirmed that children from functioning families in relation to these variables have developed skills of emotional intelligence of children from dysfunctional families.
\end{abstract}

Keywords: functional family, dysfunctional family, emotional skills, children, gender, age, family structure

\section{Introduction}

In this study, which examines the influence of functionality and dysfunctionality of families in emotional skills of children, it was presumed the existence of differences in emotional abilities of children growing up in functional families and children growing up in dysfunctional families in relation to sex, age of children and family structure. Starting from the fact that the role of the family in the development of primary personality, the research is aimed at studying the important aspect of family relations, referring to the inadequate performance of parental roles, parental neglect or abuse of parental responsibilities and rights and their impact on the childrens abilities.Accordingly, a sample of research are the children from the functional families and children from dysfunctional families which are supervised by the center of social work and in which children are mainly been neglected, and often abused. Numerous theoretical findings and the results of research shows that the lack of a good atmosphere in the family increases the emotional instability of the child, family relationships affect the emotional development, and that the child is developing in unfavorable family conditions, which is not loved, that does not feel protected, safe and happy, which is deprived of adequate incentives and exposed to stress and trauma, show serious difficulties in emotional development.

\section{Functional and dysfunctional families}

The term functional family indicate to a family where there is a relationship characterized by consistent mutual relations of its members, which is successful in carrying out its core functions and providing protection and existential security of its members. Functional families an integrated and stable group of people with appropriate understanding of values, open communication between members with mutual acceptance and encouragement, mutual care and support, which should provide interpersonal atmosphere that enhances the individuality of its members. In these families thereis respect for 
individual differences and autonomy, mutual care and support, which should provide interpersonal atmosphere that enhances the individuality of its members. In this conditions there is respect for the individual differences and autonomy.In functional families in their mutual family relations prevailing positive feelings of warmth, love and emotional security. The family as an emotional community includes interpersonal communication, which means not only information sharing, but also sharing feelings. Functional families have successfully adapted to the changes, has the adaptability and flexibility in relation to internal and external demands for change and effectively overcoming stress.

Unlike functional, dysfunctional family, do not fulfill the basic tasks and functions, do not meet the development needs of their members and do not provide conditions for the development of family members. The main feature of dysfunctional families were marred relations between family members, disrupted partner relations, disturbed relations between parents and children, the constant presence of conflict, bad behavior, neglect and abuse. Dysfunctional families are expressing emotional disconnection, the lack of mutual support, confusing and contradictory communication, non-compliance with the needs of others, the lack of co-operation and connection. Dysfunctional family, their relationships, poor parenting which includes child neglect, emotional unavailability and lack of support, adversely affect the child's development. Good family relationships usually correlated with better cognitive and social development of children, a higher level of confidence, developed social and emotional competence. Shape, structure or relations between family members in dysfunctional families adversely affect the development of children, Families that mutual relations members and attitude towards children create emotional climate that adversely affect the development of children are also dysfunctional. (Čudina - Obradović i Čudina, 2006: 297) .

The main feature of dysfunctional families are disrupted family relations. Their impact on the ability of children which are disrupted to the extent that inconsistent, irresponsible and neglecting to the rejection and the crude to violence, is the main subject of this research. In relationships with parents and other family members, children learn to recognize their own and others' emotions, feelings that are taught appropriate for certain situations that can express emotions and to what extent, and how to manage their emotions with the emotions of other people.

\section{Capabilities of emotional intelligence}

As founders of the Scientific concept of emotional intelligence are considered Peter Salovey and John D. Mayer who introduced the term in 1990 in their works on emotional intelligence. In 1995 Daniel Goleman published the book Emotional Intelligence, after which he published a number of books and articles on emotional intelligence.

The first definition of emotional intelligenceis given b Salovey and Mayer in 1990. They defined the concept of emotional intelligence as the ability to monitor and distinction of their own and others' emotions and feelings and using it as a guide in thinking and actions (Mayer and Salovey, 1999: 28).

In the opinion of the authors, thinking about feelings was dropped, they later proposed a new definition by which emotional intelligence involves the ability precise spotting, and express emotions, the ability to access and/or feelings that facilitate thinking, understanding emotions, emotional knowledge and the ability to regulate emotions in order to help the emotional and intellectual growth (Mayer and Salovey, 1999: 28). Later on, authors re-audited model and have defined emotional intelligence as the ability of perception, assimilation, understanding and managing emotions (Mayer, Caruso and Salovey, 1999). As a theoretical basis for emotional intelligence they took subspecies social intelligence (intra and interpersonal intelligence) from the Gardner theory of multiple intelligences (Gardner, 1993), as well as practical intelligence from Sternberg triarchic theory of intelligence(Sternberg, 1999).

In accordance with scientific methodology Mayer and Salovey checked and develop emotional intelligence, systematically developing models and tools for assessing emotional intelligence. In the field of measurement of emotional intelligence the most mentioned approaches tests for emotional inteligence is directly self-test for mesurement of effect emotional intelligence. Mayer and Salovey (1999) on the basis of its model constructed the first known test emotional intelligence multifactor scale for emotional intelligence (Multifactor Emotional Intelligence Scale - MEIS) consisting of 12 sub-scales divided into four classes of capabilities that include perception, assimilation, understanding, and regulation of emotion. MEIS scale showed satisfactory metric characteristics.

It is also established the connection of measured emotional intelligence with intelligence, empathy, life satisfaction and parental warmth. Factor analysis showed that the model can be reduced to three latent dimensions: perception and evaluation of emotions, understanding emotions and managing emotions, as well as the general factor of emotional 
intelligence. It is believed that this scale so far covered the broadest aspects of emotional intelligence. After that, Mayer, Caruso and Salovey have created a new test called MSCEIT as an attempt to improve the psychometric properties of MEIS. Several tests of the ability of emotional intelligence model has published in Croatia:Perceptions of emotional content test - TOES and Dictionaries emotions Test tTRE (Takšić, Harambašić and Velemir 2004 (according Takšić, Mohororić and Munjas, 2006). Kulenovic et al. constructed Emotion analysis test TAE (Arar, Takšić and Molander, 2000, according to Takšić, Mohororić and Munjas, 2006). On a sample of Croatian respondents Takšić checked empirically concept of Mayer and Salovey, in order to verify the merits, justification and usefulness of the construct, its relationship to other existing constructs and to predict certain kriteria.Takšić created a self-assessment scale - UEK 136 (Questionnaire emotional competence) based on the extended model Mayer and Salovey and, later, the edited version UEK 45 (Takšić, 2002), which measures the emotional intelligence as personality traits, but, due to frequent complaint that the intelligence can be measured only with ability test, he decided for the phrase emotional competence, in which is influenced by the recommendations of McClelland (1973), we should examine the competence of personality, not only the level of her intelligence.

\section{Methodology}

Subject of research

The subject of this empirical research is to assess the influence of functionality and dysfunctionality of families in emotional skills of children in relation to sex, age of children and family structure.

The research topic is operationally focused on:

questioning of ability to identify and understand emotions in relation to sex, age of children and the family structure,

questioning of ability to express emotions and appointments in relation to sex, age of children and the family structure,

questioning of ability to control and manage emotions in relation to sex, age of children and family structure.

The aim and objectives of research

The main objective of the research is to determine whether there is a link between functionality and dysfunctionality of family and emotional skills of children.

The scientific goal of this research is to present work that examines the impact of family life, the impact of the quality of family life in the emotional skills of children, in the scientific and professional community and to give them the importance they should have in modern society.

Social research goal is to get to comprehensive and purposeful treatment and care of children who grow up in dysfunctional families.

Hypothetically framework

The general hypothesis:

Among children who grow up in functional families and children growing up in dysfunctional families, there is significant difference in emotional abilities in relation to sex, age of the child and the family structure.

Specific hypotheses:

1. There is a statistically significant difference between children who grow up in dysfunctional families and children growing up in families in the functional level of development capabilities to identify and understand emotions in relation to sex, age of children and families struktuturu.

2. There is statistically significant difference between children who grow up in dysfunctional families and children growing up in functional families in the level of development of skills of expression and naming of emotions in relation to age, gender of the child and the family structure. 
3. There is statistically significant difference between children who grow up in dysfunctional families and children growing up in families in the degree of functional skills development regulation and management of emotions in relation to sex, age of the child and the family structure.

\section{Research methods}

To conduct the study we have used basic, general, and methods of data collection.

Basic methods of scientific and logical thinking and knowledge used in the study are analysis, synthesis, abstraction, concretization, specialization, induction, deduction and generalization.

In accordance with the type of research that has been applied we used hypothetical-deductive method, analysis, deduction, comparative and statistical method.

The choice of data collection methods have influenced the subject and objectives, the type and interdisciplinarity research. The way research is required to use the method of content analysis and test methods.

\section{Methods of testing}

Method of testing: For empirical part of the research technique used to collect data is scaling by means of instrument Emotional competence Questionnaire (Takšić, 2002) which is consists of three subscales that measure the ability of emotional intelligence: ability scale for identify and understand emotions, ability scale to express andappointments ofemotions and ability scale for regulate and control emotions.

\section{The research sample}

The study was conducted on a total sample of 114 children, devided in two groups of children aged 12 to 16 years. The first group consisted of 57 children from dysfunctional families, while the second group consisted of 57 children who grow up in functional families. Subsample of research were children from dysfunctional families selected from the population of families in which the social welfare center shall supervise the exercise of parental rights. Sub-sample surveys that are children of the functional family was selected from was the population of students in primary and secondary schools. It can be said that the sample is representative, or to reflect the structure of the population and it is adequate, which means that its size makes it possible to achieve goals and objectives of the research. Although modest in size for significant generalization, but it is a pattern that will give incentives results.

The research sample was also shown graphically, as follows: according to the age (Figure 1.), by structure (Figure 2) and according to the architecture of the family (Figure 3 ).

Figure 1. The sample of respondents in relation to age

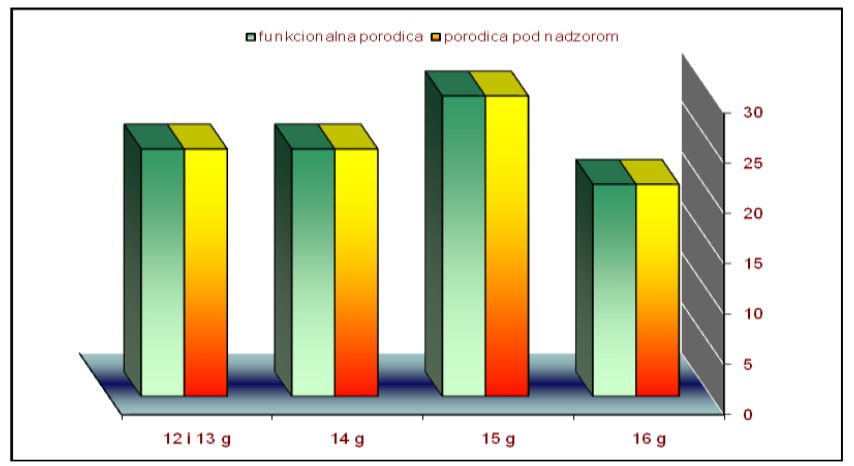


Figure 2. The sample of respondents in relation to gender

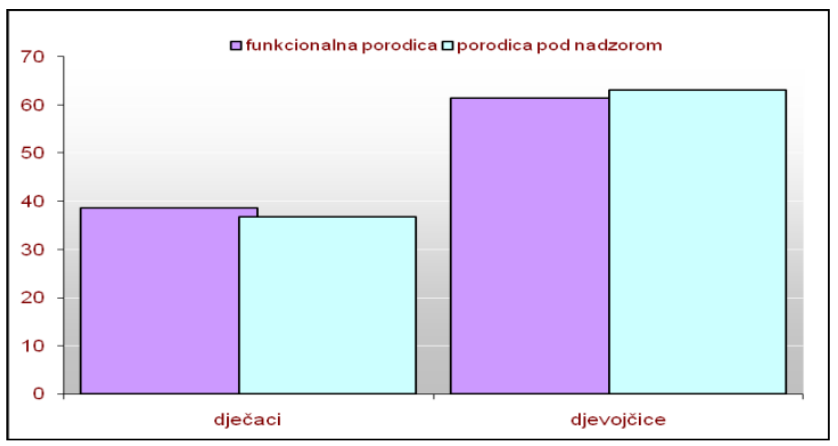

Figure 3.

The sample of respondents in relation to family structure

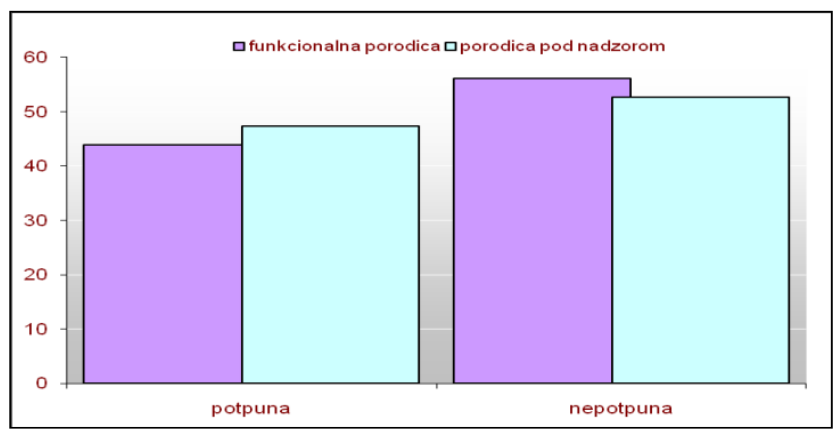

Viewing the number and the percentage of the modalities of the analyzed parameters in relation to the group, the results of the analysis of differences showing that no significant differences, and clearly defined by the boundaries of the obtained data with respect to the general data pertaining to age, gender, place of residence, family structure, and school success, confirm that the group, that in this study is composed of two independent sub-samples, rather uniform, which will enable us produce real results (table 1).

Table 1.

The significance of differences between groups of of respondents compared to general information

\begin{tabular}{|l|l|l|l|l|}
\hline & $\chi$ & $R$ & $F$ & $P$ \\
\hline age & .000 & .000 & .000 & .999 \\
\hline gender & .018 & .018 & .036 & .849 \\
\hline living place & .037 & .037 & .148 & .701 \\
\hline
\end{tabular}




\begin{tabular}{|l|l|l|l|l|}
\hline family & .035 & .035 & .138 & .711 \\
\hline success & .000 & .000 & .000 & .999 \\
\hline
\end{tabular}

It is important to note that the data in this study were collected in accordance with the Code of Ethics of Research on Children (2006).

Acquired data were processed by appropriate mathematical-statistical methods. Applying the multivariate and univariate methods. Of univariate methods was applied Roy's test, Pearson correlation of contingency coefficient (c) and the multiple correlation coefficient $(R)$, a procedure as multivariate discriminant analysis and MANOVA. The analysis is performed by the first displayed numeric and percentage values of the analyzed parameters is a distinguished difference which exists between the groups. Then was determined the statistical significance of differences between groups with respect to gender and age of of respondents, and family structure, which is not directed to the detection or rejection of the hypothesis, whereupon, as where it became to the conditions defined by characteristics of each group a certain distance and homogeneity characteristics and contribute to the characteristics of each group.

\section{Research results}

1. Capabilities to identify and understand the emotion, expression and appointment of emotions and emotion regulation and management.

In tables 2, 3 and 4. are shown number and the percentage values of emotional ability: the identification and understanding of the emotion, expression, and the designation of emotion regulation and control and emotions, by the groups of respondents.

Table 2. Capabilities to identify and understand emotions

\begin{tabular}{|l|l|l|l|l|l|l|}
\hline & \multicolumn{2}{|l|}{ poorly developed } & \multicolumn{3}{l|}{ moderately developed } & \multicolumn{2}{l|}{ highly developed } \\
\hline & n & $\%$ & $n$ & $\%$ & n & $\%$ \\
\hline functional family & y18. & 31.6 & 20. & 35.1 & 19. & 33.3 \\
\hline $\begin{array}{l}\text { dysfunctional } \\
\text { family }\end{array}$ & 23. & 40.4 & 16. & 28.1 & 18. & 31.6 \\
\hline
\end{tabular}

The table analysis reveals that most of the subjects in the group of children from a functional family has a moderately developed capacity to identify and understand emotions (20 respondents $35.1 \%$ ), while in the group of children from dysfunctional families, most respondents have poorly developed skills (23 respondents $40.4 \%$ ). Due to the fact that $p=$ $.582 \mathrm{c} 2$ - test, it can be said that there is no connection between the group and the ability to identify and understand emotions, and the value of $\mathrm{c}=.097$ indicates that the correlation is very low.

According to the obtained data shown in Table 3 , in the group of children from the functional family most individuals have a highly developed capability of expression and appointment emotion (22 subjects $38.6 \%$ ), while in the group of children from dysfunctional families, the majority of subjects have a poorly developed abilities (22 subjects $38.6 \%)$. There is no connection between the group and the ability to express emotions and appointment, because the $p=.209 \mathrm{c} 2$ - test, and $c$ $=.163$ shows that the correlation is very low.

Table 3. Ability to express and appointment emotions

\begin{tabular}{|l|l|l|l|l|l|l|}
\hline \multicolumn{2}{|l|}{ poorly developed } & \multicolumn{2}{l|}{ moderately developed } & \multicolumn{2}{l|}{ highly developed } \\
\hline & n & $\%$ & $n$ & $\%$ & $n$ & $\%$ \\
\hline functional family & 15. & 26.3 & 20. & 35.1 & 22. & 38.6 \\
\hline
\end{tabular}




\begin{tabular}{|l|l|l|l|l|l|l|}
\hline $\begin{array}{l}\text { dysfunctional } \\
\text { family }\end{array}$ & 22. & 38.6 & 21. & 36.8 & 14. & 24.6 \\
\hline
\end{tabular}

Table 4. Ability to regulate and control emotions

\begin{tabular}{|c|c|c|c|c|c|c|}
\hline & \multicolumn{2}{|c|}{ poorly developed } & \multicolumn{2}{|c|}{ moderately developed } & \multicolumn{2}{|c|}{ highly developed } \\
\hline & n & $\%$ & n & $\%$ & n & $\%$ \\
\hline functional family & 16. & 28.1 & 23. & 40.4 & 18. & 31.6 \\
\hline $\begin{array}{l}\text { dysfunctional } \\
\text { family }\end{array}$ & 22. & 38.6 & 17. & 29.8 & 18. & 31.6 \\
\hline
\end{tabular}

Table 4 shows that the majority of respondents in the group of children from a functional family has a moderately developed capacity for emotion regulation and management (23 respondents $40.4 \%$ ). In the group of children from families under the supervision the largest number of respondents have poorly developed skills (22 respondents $38.6 \%$ ). Statistically, as $p=$ $.397 \mathrm{c} 2$ - test, one can say that there is no connection between the group and the ability to control and manage emotions, and given the fact that $\mathrm{c}=.126$, correlation is very low.

2. Differences between groups in emotional abilities in relation to: age (12-13 years, sex (male) and family structure (incomplete)

In accordance withset hypothesis it has been examined whether there is a statistically significant difference in the level of emotional ability between the groups of children from functional families and groups of children from dysfunctional families in relation to age $(12-13,14,15$ and 16), in relation to gender (male and female) in relation to family structure (complete and incomplete). The results showed that the difference is determined and clearly defined boundaries between the groups in relation to the emotional skills and age (12-13 years), emotional skills and gender (male) and emotional skills, and family structure (incomplete).

\section{Emotional skills and age (12-13 years)}

Statistically significant differences between groups of respondentsit was confirmed, in relation to the level of development of emotional ability, for the age (12-13 years). Using the analysis values of which are $p=.011$ (MANOVA analysis) and $p=$ .011 (discriminant analysis), has shown that there is a difference and clearly defined boundaries between groups of respondents. Also, the value of $p<.1$ which are shown in Table 5, show that there is significant difference between the group of subjects with the ability to identify and understand emotions (.005), and ability to express and appointment emotion (.001) as vell as and the ability to regulate and control emotions (. 027).

Table 5. Significance of differences among groups in relation to emotional ability (12-13 year old)

\begin{tabular}{|l|l|l|l|l|l|}
\hline & $\chi$ & $R$ & $F$ & $l$ & $k$ k.dsk \\
\hline identify and understand emotions & .462 & .521 & 9.665 & .005 & .081 \\
\hline express and appointment emotion & .497 & .572 & 12.660 & .001 & .174 \\
\hline regulate and control emotions & .385 & .417 & 5.472 & .027 & .000 \\
\hline
\end{tabular}

Based on the discriminant analysis results $p=.011$, which indicates that there is no clearly defined boundary between the groups of respondents were determined by characteristics of each group in relation to emotional ability (age 12-13), and the homogeneity of groups distance.

Table 6. Characteristics and homogeneity of the groups in relation to emotional ability (age 12-13) 


\begin{tabular}{|l|l|l|l|}
\hline & functional family & dysfunctional family & dpr \% \\
\hline $\begin{array}{l}\text { express and appointment } \\
\text { emotion }\end{array}$ & highly developed * & poorly developed * & 68.235 \\
\hline $\begin{array}{l}\text { identify and understand } \\
\text { emotions }\end{array}$ & & poorly developed * & 31.765 \\
\hline regulate and control emotions & & poorly developed * & .000 \\
\hline $\mathrm{n} / \mathrm{m}$ & $12 / 14$ & $8 / 14$ & \\
\hline$\%$ & 85.71 & 57.14 & \\
\hline
\end{tabular}

As presented in table 6 , the status of each group sub-samples is mostly determined by the ability of expressing emotions and appointments, because the contribution of the characteristics are $68.24 \%$, followed by the ability to see and understand emotions (31.76\%). The homogeneity of the group of children from a functional family is $85.71 \%$, and the homogeneity of the group of children from families under the supervision are $57.14 \%$. Based on these results which are related to emotional ability (age 12-13), it was possible to determine the properties of each group. Group - children from functional family has the ability to express themselves and appoint emotions has the status - highly developed, while the group - children from dysfunctional families, have the following characteristics: the ability to express themselves and naming emotions has the status - poorly developed, the ability to identify and understand emotions has the status - poor developed, and the ability to regulate and control emotions has the status - poorly developed.

Distance (Mahalanobis) between the groups subjects (1.46) compared to the emotional ability (age 12-13) showed that there are differences that there is a distance between the groups of respondents.

\section{Emotional skills and gender (male)}

There is statistically significant differences between groups of respondents, in comparison to the emotional abilit. It was confirmed for the variable gender (male) on the basis of the value $p=.042$ (MANOVA analysis) and $p=.046$ (discriminant analysis), which showed that there is a difference and clearly-defined boundary between the groups of respondents. In Table 7. it is shown that the value of $p<.1$ confirmed that there is a significant difference between the group of subjects with the ability to regulate and control emotions (.006).

Table 7:

Significance of differences between groups of respondents in relation to emotional ability (half male)

\begin{tabular}{|l|l|l|l|l|l|}
\hline & $\chi$ & $R$ & $F$ & $p$ & k.dsk \\
\hline $\begin{array}{l}\text { identify and understand } \\
\text { emotions }\end{array}$ & .174 & .176 & 1.315 & .258 & .025 \\
\hline $\begin{array}{l}\text { express and appointment } \\
\text { emotion }\end{array}$ & .135 & .136 & .770 & .385 & .000 \\
\hline regulate and control emotions & .382 & .414 & 8.468 & .006 & .173 \\
\hline
\end{tabular}

After determining the difference between the measured groups were determined by the characteristics and the homogeneity of each group of respondents, as well as the distance between them (Table 8).

Table 8. Characteristics and homogeneity of the groups in relation to emotional capacity )gender-male)

\begin{tabular}{|l|l|l|l|}
\hline & Functional family & Dysfunctional family $\%$ \\
\hline
\end{tabular}




\begin{tabular}{|l|l|l|l|}
\hline identify and understand emotions & moderately developed * & poorly developed * & 87.374 \\
\hline regulate and control emotions & & & 12.626 \\
\hline express and appointment emotion & - & & .000 \\
\hline $\mathrm{n} / \mathrm{m}$ & $13 / 22$ & $17 / 21$ & \\
\hline$\%$ & 59.09 & 80.95 & \\
\hline
\end{tabular}

The characteristic of each subsample groups is mostly defined by ability to regulate and control emotions, because the contribution of the characteristics are $87.37 \%$, followed by the ability to identify and understand emotions (12.63\%). The homogeneity of the group of children from a functional family is $59.09 \%$, and the homogeneity of the group of children from families under the supervision of $80.95 \%$.

Based on the results for emotional skills (gender - male), it can be said that the group - children from functional family has the ability to regulate and control emotions property - moderately developed, a group - children from families under the supervision of the ability to regulate and control emotion has the status of - poorly developed.

Distance (Mahalanobis) of the obtained (0.94) showed that there is a difference, and that the distance of the obtained moderately.

\section{Emotional skills and family structure(incomplete family)}

Statistically significant differences between groups of respondents in comparison to the degree of development of emotional ability, and it was confirmed for the structure of the variable family (incomplete), by using the values $p=.138$ (MANOVA analysis) and $p=.069$ (discriminant analysis). Analysis showed that there is no difference, but that is no clearly defined boundary between the groups, which is indicative that there are probably latent attributes which in interaction with other features (synthesized) contribute to the discrimination of the group. A starting unit, therefore a system of three features is reduced system of two features, where it was found that there is a difference and the boundary exists between groups.

Table 9: Significance of differences between the groups in accordance with an emotion. capabilities

(structures of the incomplete)

\begin{tabular}{|l|l|l|l|l|l|}
\hline & $\chi$ & R & F & P & k.dsk \\
\hline identify and understand emotions & .161 & .163 & 1.636 & .206 & \\
\hline $\begin{array}{l}\text { express and appointment } \\
\text { emotion }\end{array}$ & .239 & .246 & 3.855 & .054 & .023 \\
\hline regulate and control emotions & .254 & .262 & 4.431 & .039 & .032 \\
\hline
\end{tabular}

As presented in Table 9. the $p<1$, which means that there is a significant difference between the group of subjects with the ability of expressing emotions and appointments (.054) and the ability of emotion regulation and control system (.039), and that $p>$.1. This means that no significant differences were observed between the group of subjects with the ability to identify and understand emotions (.206). Discrimination coefficient indicates that the largest contribution to the group of respondents discrimination in relation to the emotional skills (family structure is incomplete), with the ability to control and manage emotions (.032), and then with the ability to express emotions and appointments (.023). After determining the difference between the measured, groups were determined by the characteristics and the homogeneity of each group of subjects, as well as the distance between them, because with $p=.069$, discriminant analysis, demonstrated that no clearly defined boundary between the groups of respondents, and it is possible to determine the characteristics of each - in relation to the emotional ability (the family structure is incomplete).

Table 10. Characteristics and homogeneity of the groups in relation to emotional ability 
(the structure of the family - incomplete).

\begin{tabular}{|l|l|l|l|}
\hline & Functional family & Dysfunctional family & dpr \% \\
\hline regulate and control emotions & & poorly developed & 58.182 \\
\hline $\begin{array}{l}\text { express and appointment } \\
\text { emotion }\end{array}$ & & poorly developed & \\
\hline identify and understand emotions & & poorly developed & 41.818 \\
\hline $\mathrm{n} / \mathrm{m}$ & $22 / 32$ & $17 / 30$ & .000 \\
\hline$\%$ & 68.75 & 56.67 & \\
\hline
\end{tabular}

As can be seen from Table 10, each subsample of groups is most defining by level of ability to regulate and control emotions, because the contribution of the characteristics are $58.18 \%$, followed by the ability to express emotions and appointments $(41.82 \%)$. The homogeneity of the group of children from a functional family is $68.75 \%$, while a group of children from families under the supervision are $56.67 \%$.

Based on the results for emotional skills (family structure is incomplete), it is possible only for a group of children from families under the supervision allocate the following properties: the ability to control and manage emotions - poorly developed, the ability to express themselves and appointment emotions - underdeveloped and the ability to control and management of emotions - poorly developed.

Mahalanobis distance (0.61) indicates that there is a difference and that there is a moderate distance between groups of respondents of children from functional families and children from families under supervision.

\section{Discussion}

Based on the results obtained by a descriptive method, related to determining the difference between the groups of children who grow up in functional families and children growing up in dysfunctional families was possible to extract the characteristics of each group, which is in fact the aim of the research.

In relation to the ability of expression and appointment emotions, group - children from functional family has a badly expressed trait - highly developed skills, a group - children from dysfunctional families, have poor expressed trait - poorly developed skills, as well as in relation to the ability of regulation and control of emotions.Group - children from poor functional family has expressed trait - moderately developed skills, a group - children from dysfunctional families, have expressed weak property - poorly developed skills. In relation to the ability to identify and understand emotions group of children from functional family has a moderately developed abilities to identify and appointment emotions, while a group of children from dysfunctional families, have these skills poorly developed.

According to the proposed hypotheses,as can be seen from the results, it is determine the presence of statistically significant difference in the level of emotional ability between the groups of children from the functional families and children from dysfunctional family, in relation to the age (12-13 years old, 14 years 15 years and 16 years), family structure (complete and incomplete), and gender (male and female). Starting from interpretations give by JD Mayer and P. Salovey (1999), as well as obtained results of their research that emotional skills begin to develop in the parental home to good relations between parents and children, that parents help children identify emotions, that students who need emotional education mostly come from families in which emotional communication in some way distorted, because they have already adopted maladaptive emotional reactions to humiliation, that children from families with disturbed family relationships often experience can be an obstacle to the development of emotional competencies. There are matching control styles of parents and their children. This study are based on the assumption that children from families that are considered functional and children from families with disturbed family relationships differ in the level of development of emocional skills in relation to sex, age of children and family structure. 
The results showed that the is determined difference and clearly defined boundaries between the groups in relation to the emotional skills and age (12-13 years), emotional skills and gender (male), emotional skills and family structure (incomplete). It was possible to define characteristics, homogeneity of the group and the distance between them.

Based on the results conducted for emotional abilities (age 12-13 years), it can be concluded that it is possible to determine the properties of the group. It is also posible to determine that group - children from functional family has the ability to express emotions and appointment feature - a highly developed capabilities, while a group of children from families under supervision has the following properties: the ability to express emotions and appointment has the status of - poorly developed, the ability to identify and understand emotions - underdeveloped and the ability to control and manage emotions, has the status of - poorly developed.

For variable family structure (incomplete) in relation to emotional ability allocate properties was only possible for the group - children from families under the supervision for: the ability to regulate and control emotions - poorly developed, the ability to express themselves and appointment emotions - underdeveloped and the ability to control and management of emotions - poorly developed.

Ability to regulate and control the emotions related to the ability to consciously control our own emotions, and the ability to adequately reign feelings and impulsesthat interfere, as well as positive guidance of self conduct. Self-regulation includes the ability to adjust the internal states and control their own behavior arising from the internal state. Managing emotions means the impact on their own feelings and their expression, as well as compliance with the requirements of expression environment. Emotional regulation refers to this kind of emotional control, how intense or calm an individual show his emotion, self-mastery, managing emotions, etc. It is believed that the individual differences in emotionality, and in particular the ability to regulate and control the emotions associated with the quality of social functioning children, and that the child has developed self-control is likely to behave non-aggressive and will not have problems with their peers. The assumption of the existence of differences in emotional abilities between children who grow up in functional families and children growing up in dysfunctional families, based on the interpretation that the children can learn maladaptive strategies for regulating emotions watching parents who are angry, depressed or constantly arguing, as it can learn custom ways to regulate emotions by observing parents who communicate in a positive and qualitative way, and the fact that children who are exposed to scenes of violence, or who are direct victims of violence can develop maladaptive control strategy, precisely because they can not understand such experiences without the help of adult person.It is also taken into account that the ability to control their own emotions has adaptive function, and that extremely adverse conditions of socialization which exist number of stressful life events, as the result often have an emotional regulation and control, which may be nonadaptive. For regulation and control, Mayer and Salovey (1999) suggest that the highest level of structural segments of the model of emotional intelligence, and Takšić (2004), who is the author of the instrument which is used in this study, the expression emotion regulation and control means effects the emotions have the thinking, memory and behavior of individuals, and the ability to control emotions.

The obtained results showed that, relative to those of emotion regulation and control groups of subjects from the functional and from dysfunctional families differ in the level of regulation and control capabilities emotions in ordnence to variable gender (male) and thevariable age (12-13 years ) in relation to family structure (incomplete). The question that often arises when considering the abilities of emotional intelligence is not only whether there are differences in the level of development of emotional skills in relation to gender, but also the question of whether men and women differ with the ability to control and manage emotions, because they imply conscious ability to manage their own emotions and the ability of adequate feelings control and impulses that interrupt, which are believed to be characteristic for the male gender. Results of obtained research by Brody (1985), on the basis of the research results, which deals with the difference in half in the expression and recognizing emotion, indicating the existence of differences between genders in several areas of emotional functioning, relating to the non-verbal sensitivity, expression and own reports the fear, anger, sadness. Chaplin and Aldo (2013), in their very extensive research, which is engaged in establishing the differences between the sexes in the emotional expression, confirming the existence of significant differences in the emotional expression in boys and girls. The results showed that girls express more positive feelings and emotions such as sadness and anxiety, while boys show more external emotions like anger.

Results of this study showed differences between the sexes in the ability to regulate and control emotions. It is important to note that the results show that the group of children from a functional family has developed the ability to regulate and 
control emotions, according to the interpretation of that self-control is associated with the quality of social functioning children, and that development is largely determined by family relationships.

Parke (1994, according to Mayer, Salovey, 1999), analyzes the impact of parents and their behavior on the emotional skills of children. He believed that parents socialize emotions in their children as indirect observation of parental and family relations, and teaching by parents and regulation opportunities for practicing life (exposing to situations), which also supports the proposition that there are differences in emotional skills of the groups of children who grow up in functional families and groups of children growing up in dysfunctional families. These differences are observed in the respondents from families which are incomplete because one parent does not live with the children in a family community, and that these differences were observed at the lowest age group (12-13 years), during the period when the influence of parents is still predominant.

Research results confirmed (Davies, Harold, Goeke-Morey and Cummings 2002, Almeida, Wethington, and Chandler, 1999) that a significant impact of the child's sense of insecurity and creating adverse family atmosphere are: disturbed partnerships, conflicts among parents, poor quality parenting, emotional lack of adjustment, emotional development, and the emergence of emotional problems. Research conducted by Einsberg et al. (2005) showed that the most neglected and abused children exhibit reduced or excessive control behaviors, and social-emotional maladjustment. Izard (2002) discusses the importance of quality commitment in the first year of life the child to develop positive emotions and selfregulation as significant factors in addition to attachment points out the absence of maternal depression, maternal stress and positive expression. Izard speaks of the need for a child to grow up in a favorable family atmosphere in which acquires a sense of security, emphasizes the importance of establishing good emotional relationship with their parents, warm relationship with his mother and those that meet the needs of the child, but also the need to ensure the child the opportunity to learn appropriate emotional expression for the acquisition of emotional skills, which includes the identification, recognition, understanding and appointment their own and others' emotions, as well as opportunities to learn empathy and prosaically response.

The opinions of these and other authors, as well as the results of their research, confirms that this is how children express their emotions and what control abilities have related to their functioning in the family and that parental emotional expression affects indirectly the emotional competence of children. This was certainly taken into mind when we assumed that in relation to the emotional ability to distinguish children from functional families and children from dysfunctional families. Earlier we already mentioned the view according to which the children's emotions and expressing emotions associated with the quality of parent-child relationships, located in modern conceptualizations of attachment between parents and children. The results showed that in relation to the ability to appointments and express emotion, from groups of functional and from dysfunctional families differ in relation to these variables: family structure (incomplete) and age (12-13 years old) which confirms that the reduced influence on the development of parent emotional skills, due to the absence of one parent or the other parent due to the inability to fully devote needs of the child and its development. These differences are present at a younger age when the influence of parents is still predominant influence of other factors of socialization. The results showed that the group of children from a functional family has developed the ability to express and appointments emotions, in line with the assumption of this research that is based on the fact that the ability of expression and appointments of emotions includes the ability to recognize their emotions and the ability to perceive the emotions of others. This is because parents can teach their children how and when to express their emotions, how to interpret the outpouring of emotions and emotional behavior, as well as how to manage their emotions in order to be able to act appropriately. On this basis, it can be assumed that parental actions associated with emotions affect the way on children express their emotions and their ability to adequately regulate emotions and emotions fueled behavior. What should be noted is that, no matter what number of empirical studies dealing with the role of parents in the child's expression of emotion is limited, however, is certain that there is an impact, and that it is important for the expression of children's emotions, which was confirmed with results of this study relating to the appointment and the ability to express emotion. Ability to identify and understand the emotions related to the ability to see and understand the emotions and the ability to apply emotionally knowledge. The obtained study results showed that in relation to the ability to identify and understand emotions from the functional and from dysfunctional families differ only in variable - age (12-13 years). Understanding their emotions and other people is an important form of emotional development and identified as emotional literacy. Claude Steiner says that when we are emotionally literate means that we feel emotions that are in us, to know who and how many are strong, and that we know what causes them in us and in others. We then learn how, when and where to express and control (Steiner, 1996: 33). Empathy presents basis of prosocial behavior, meaning awareness of the feelings of other people, understanding the emotions of other people and 
showing others to understand their emotions. As with self-control, a major role in the development of empathy, except cognition and speech has the behavior of the parents. Cook, Greenberg, Kusche (1994) in their research came to the results that show that children who have behavioral problems, while a deficit in understanding the emotions that there is a negative correlation between intellectual functioning and behavioral problems and intellectual capacities reduce the effects of behavioral problems in the understanding of emotions. Longitudinal studies by Zou, Eisenberg, bad, Fejbs, Riser et al. (Zhou, Eisenberg, Losoya, Fabes, Reiser et al., 2002, cited in Collins, A. and Obradović, 2006: 336) showed that the most affected on child empathy is gentle and mother with positive emotions.

\section{Conclusion}

Due to the specificity of emotional intelligence that contributes to great interest in this construct, is reflected in the assumption that emotional intelligence can be developed, and affecting the development of emotional intelligence as a significant factor. Many authors point out just family and family relations, the premise of this study was that there are differences in emotional abilities of children growing up in functional families and children growing up in dysfunctional families. Almost all the authors who have dealt with emotional intelligence confirmed that this is how children express their emotions and what control capabilities are related to their functioning in the family, and that parental emotional expression affects the emotional competence of children, which certainly we have to had in mind when assumed to be in relation to the emotional ability to distinguish children from functional families and children from dysfunctional families.

The results showed that the difference is determined and clearly defined boundaries between the groups in relation to emotional abilities and variables: age (12-13 years), gender (male) and family structure (complete), and that it was possible to define the characteristics, homogeneity of group and the distance between them, which confirms that children from functional families in relation to these variables have developed skills of emotional intelligence.

\section{References}

[1] Almeida, D. M., Wethington, E. i Chandler, A. L. (1999). Daily transmissions of tensions between marital dyads and parent-child dyads. Journal of Marriage and the Family, 61, 49-61.

[2] Bowlby, J. (1988). Secure Base: Clinical Applications of Attachment Theory. London: Routledge.

[3] Brody L. (1985). Gender differences in emotional development. A review of theories and research. Journal of Personality, 53, 102-149.

[4] Chaplin, T. M. i Aldao, A. (2013). Gender differences in emotion expresion in children: A meta-analytic review. Psychological bulletin, Vol. 139 (4), 735-765.

[5] Cook, E.T., Greenberg, M.T. \& Kusche C.A. (1994). The relations between emotional understanding, intellectual functioning and disruptive behavior problems in elementary school aged children. Journal of Abnormal Child Psychology, 22, 205-219.

[6] Čudina-Obradović, M. i Obradović, J. (2006). Psihologija braka i obitelji. Zagreb: golden marketing - Tehnička knjiga

[7] Davies, P. T., Harold, G. T., Goeke-Morey, M.C. i Cummings, M. E. (2002). Child emotional security and interparental conflict. Monographs of the Society for Research in Child Development, 67, 3, No 270.

[8] Eisenberg, N., Sadovsky, A., Spinrad, T. L., Fabes, R. A., Losoya, S. H., Valiente, C., Reiser, M., Cumberland, A. i Shepard, S. A. (2005). The relations of problem behavior status to children's negative emotionality, effortful control, and impulsivity: Concurrent relations and prediction of change, Developmental Psychology, 41, 193211.

[9] Ekerman, N. V. (1966). Psihodinamika porodičnog života, dijagnoza i liječenje porodičnih odnosa. Titograd: Grafički zavod.

[10] Gardner, H. (1993). Multiple intelligence: The Theory and Practice. New York.

[11] Haley, J. (1980). Leaving home: a therapy for disturbed young people. New York: McGraw Hill. 
[12] Goldner-Vukov, M. (1988). Porodica u krizi. Beograd: Medicinska knjiga

[13] Izard, C. E. (2002). Translating emotion theory and research into preventive interventions. Psychological Bulletin, 128, 796-824.

[14] Kulenović, A., Balenović, T. i Boško, V. (2000). Test analize emocija: Jedan pokušaj objektivnog mjerenja sposobnosti emocionalne inteligencije. Suvremena psihologija, 3, 1-2, 27-48.

[15] Mayer, J. D. i Salovey, P. (1999). Što je emocionalna inteligencija? U: P. Salovey i D. Sluyter. (ur.). Emocionalni razvoj i emocionalna inteligencija, pedagoške implikacije. str. 19-54. Zagreb: Educa.

[16] Mayer, J. D., Caruso, R. D. i Salovey, P. (1999). Emotional intelligence meets traditional standards for an intelligence. Intelligence, 27, 267-298.

[17] Mc Clelland, D. (1973). Testing for competence rather than for „inteligence“. American Psychologist, 28, $1-14$.

[18] Nagradić, S. i sar. (2006). Etički kodeks istraživanja o djeci. Sarajevo: Vijeće za djecu Bosne i Hercegovine.

[19] Polovina, N. (2007). Osećajno vezivanje. Beograd: Institut za pedagoška istraživanja.

[20] Steiner, C. M. (1996). Emotional literacy training: The application of transactional analysis to the study of emotions. Transactional Analysis Journal, 26, 31-39.

[21] Sternberg, R. J. (1999). Uspješna inteligencija. Zagreb: Barka.

[22] Takšić, V. (2002). Upitnici emocionalne inteligencije (kompetentnosti) UEK. u: K. Lacković-Grgin \& A. Proroković \& V. Ćubela \& Z. Penezić (Eds.). Zbirka psihologijskih skala i upitnika: Svezak I (pp. 27-43). Zadar: Filozofski fakultet.

[23] Takšić, V. (2004). Skala emocionalne regulacije i kontrole (ERIK). Provjera faktorske strukture. Psihologijske teme, 11, str. 43-54.

[24] Takšić, V., Mohororić, T. i Munjas, R. (2006). Emocionalna inteligencija: operacionalizacija, primjena i povezanost sa pozitivnom psihologijom. http://www.hrcak.hraccessed: 03. 08. 2008. at $11 \mathrm{pm}$ 